\title{
Determination of output-input ratio of mobile machine wheeled mover
}

\author{
Nikolay Artyomov ${ }^{1}$, Mikhail Podrigalo $^{1}$, Aziz Abdulgazis $^{2, *}$, and Umer Abdulgazis ${ }^{2}$ \\ ${ }^{1}$ Kharkiv Petro Vasylenko National Technical University of Agriculture, Ukraine \\ ${ }^{2}$ Crimean Engineering and Pedagogical University, Lane training, 8, Simferopol, 295015, \\ Simferopol, Republic of Crimea, Russian Federation
}

\begin{abstract}
The output-input ratio of a car wheel depends on power losses induced by tyre deformation. Wheel static, kinematic and dynamic radii depend on the tyre deformation radii and, consequently, predefine the mover output-input ratio. This article proposes a method to asses an instantaneous output-input ratio of a wheeled mover as a ratio between a wheel kinematic radius and dynamic radius on the basis of the analysis of the previously conducted research.
\end{abstract}

\section{Analysis of recent achievements and publications}

Car wheel contact and static $r_{c m}$, kinematic $r_{\kappa}$ and dynamic $r_{\partial}$ wheel radii are the issues covered in a significant number of research conducted by various authors [1-9].

The wheel tyre, being an elastic body, cannot be considered within classical mechanics as the research object is a solid body and not a deformed one. That is why the author's position and intention to present unappealable truth in the paper [1] are slightly unjustified. The evaluation of energy losses occurring at wheel rolling has recently attracted the attention of most researchers $[2,3,9]$. The problems arising at the definition of a wheeled mover output-input ratio are caused by a biased choice of a research "useful effect". This is the reason different authors argue on how to define a car output-input ratio. We consider a useful effect as such which is impossible to avoid or decrease by a rational object synthesis.

The authors of the research $[4,5,6,7,8,9]$ link energy losses in a wheeled mover with a wheel radius (kinematic $r_{\kappa}$ and dynamic $r_{\partial}$ ). The paper [8] considers the ratio of a car drive wheel dynamic and kinematic radii in terms of energy losses and assumes the drive wheel dynamic radius is not dependent on the value of the input torque. It is demonstrated [8] that, due to the losses caused by the internal and external friction, a kinematic radius is lower than a dynamic one while at wheel slipping its value reduces to zero. The torque influence analysis confirms the linear nature of the kinetic radius value decrease [8]. On the contrary, in the case of a driven wheel, a wheel kinematic radius $r_{\kappa}$ is larger than a dynamic one $r_{\partial}$. According to the data presented in the papers $[6,10]$, the following ratio is applicable to a driven wheel

$$
r_{\kappa}=(1.03-1.06) \cdot r_{\partial}
$$

\footnotetext{
*Corresponding author: aziz.abdulgazis@mail.ru
} 
In the paper [7], with the reference to the previously conducted research[11], the authors point out some inconsistencies in relation to the definition of the resistance towards wheel rolling on the basis ofthe equations of the power and force balance.

In the paper [11] we consider the equations of power and force balances of a car drive wheel.

$$
\begin{gathered}
N_{t}=M_{\kappa} \cdot \omega_{\kappa-} P_{x} \cdot V_{a} ; \\
R_{z} \cdot a=M_{\kappa}-R_{x} \cdot r_{\partial}
\end{gathered}
$$

where $N_{t}$ - power lost by the wheel at its rolling (rolling resistance power);

$M_{\kappa} ; \omega_{\kappa}$ - torque at the driving wheel and its angular rate;

$P_{x}$ - longitudinal force applied to the wheel on the body side;

$V_{a}$ - car speed (minimum speed of the wheel axis).

$$
V_{a}=\omega_{\kappa} \cdot r_{\kappa}
$$

$R_{z}$-normal road response to the wheel;

$a$ - drift of the vector of a normal $R_{z}$ road response to the wheel (friction factor, rolling factor).

$R_{x}$ - tangential road response to the wheel, $R_{x}=-P_{x}$.

By dividing the left and right parts of the equation (2) into $\omega_{\kappa}$, the authors of the papers $[7,11]$ obtained the following equations taking into account the ratio (4)

$$
M_{f}=M_{\kappa}-P_{x} \cdot r_{\kappa}
$$

where $M_{f}$ - moment of wheel rolling resistance. Taking into account that

$$
R_{z} a=M_{f}
$$

transform the expression (3) to the form:

$$
M_{f}=M_{\kappa}-P_{x} \cdot r_{\partial}
$$

Comparing the expressions (5) and (7), we can see inconsistencies as $r_{\partial} \neq r_{\kappa}$. On the foregoing basis, the author of the paper [7] drew a conclusion that the resistance moment (5), obtained from the power balance equation (2), differs from the resistance moment (7) obtained from the force balance condition (3). Also, the difference in the moments, correspondingly obtained from the equation of power and force balances, is expressed by the formula:

$$
\triangle M_{f}=R_{x}\left(r_{\partial}-r_{\kappa}\right)
$$

The author of the paper [7] explains the considered discrepancy by a wrong interpretation of the physical sense of the rolling resistance moment $M_{f}$ included in the equation (5) and obtained $N_{t}$ (rolling resistancepower) on the wheel angular rate $\omega_{\kappa}$. The authors [7] believe that the rolling resistance moment includes not only hysteresis losses but also the losses due to the friction in the contact area pattern. However, the paper [12] demonstrated that the friction in the contact area pattern also causes the drift of a normal road response vector.

In our opinion, the underlined inconsistencies are explained by the fact that the authors of the known papers $[1,7,11]$ considered the car wheel dynamics within classical mechanics which considers only solid bodies (bodies with permanent distances between their points). 
From this point of view $r_{\partial}=r_{\kappa}$ and arising inconsistencies disappear (see the equations (5) and (7)).

To explain the specified inconsistencies, it is necessary to consider the car wheel rolling process withinthe elasticity theory and take into account the deformations of wheel components. At the solving of the specified problem it is necessary to link the wheel output-input ratio, kinematic and dynamic radii.

\section{Purpose and research objectives setting}

The research purpose is to define an instantaneous, power and cyclic output-input ratios of a car drive wheel.

To reach the set purpose, one needs to identify the interconnection between kinematic and dynamic radii and the car drive wheel output-input ratio.

\section{Statement of basic material}

Kinematic and dynamic radii can be obtained with the help of the following dependencies:

$$
\begin{aligned}
& r_{\mathrm{K}}=V_{a} / \omega_{\mathrm{K}} ; \\
& r_{\mathrm{A}}=\mathrm{M}_{\mathrm{K}} / \mathrm{P}_{\mathrm{K}}
\end{aligned}
$$

where $\mathrm{P}_{\mathrm{K}}-$ traction force applied to the wheel axis.

The instantaneous output-input ratio of the car drive wheel can be defined as follows:

$$
\eta_{\mathrm{K}}^{\mathrm{MгH}}=\frac{N \text { пол }}{N \text { затр }}=\frac{\mathrm{P}_{\mathrm{K}} \cdot V_{a}}{M_{\mathrm{K}} \cdot \omega_{\mathrm{K}}}
$$

Where

$$
N_{\text {пол }}=\mathrm{P}_{\mathrm{\kappa}} \cdot V_{a} ;
$$

Nзатр - power delivered to the wheel from the car transmission

$N_{\text {затр }}=M_{\mathrm{K}} \cdot \omega_{\mathrm{K}}$;

In the equation (11):

$$
\frac{\mathrm{P}_{\mathrm{K}}}{M_{\mathrm{K}}}=\frac{1}{r_{\mathrm{A}}}
$$

and

$$
\frac{V_{a}}{\omega_{\mathrm{K}}}=r_{\mathrm{K}}
$$

After the substitution of (13) and (14) in (11) we obtain:

$$
\eta_{\mathrm{K}}^{\mathrm{M \Gamma H}}=r_{\mathrm{K}} / r_{\text {д }}
$$

The obtained expression for the definition of the instantaneous output-input ratio of a wheeled mover takes into account all the internal power losses in a tyre except for the rolling resistance caused by the drift of the road normal response in relation to the direction the normal load vector acts on the wheel. It should be mentioned that the wheel rolling resistance is predetermined by the specified drift and relates to the occurring efforts of 
useful (production) resistance, which is proved in the papers [12-13]. That is why, at the definition of a wheeled mover output-input ratio, one may not take them into account.

To evaluate the correctness of the obtained result, we write the equation (2) for the power balance of the car drive wheel in the following form:

$$
N_{\mathrm{\kappa}} \eta_{\mathrm{\kappa}}^{\mathrm{M \Gamma H}}=N_{\text {затр }}^{\mathrm{MrH}} \eta_{\mathrm{\kappa}}^{\mathrm{MrH}}=N_{t}+P_{x} \cdot V_{a}
$$

Where $N_{t}$ - power of the wheel rolling resistance force induced by the drift of a normal road response,

$$
N_{t}=\mathrm{a} \cdot R_{\mathrm{z}} \cdot \omega_{\mathrm{K}}
$$

The equation (16) with the account of (4),(12),(15),(17) takes the form:

$$
M_{\mathrm{K}} \cdot \omega_{\mathrm{K}} \cdot \frac{r_{\mathrm{K}}}{r_{\mathrm{H}}}=\mathrm{a} \cdot R_{z} \cdot \omega_{\mathrm{K}}+P_{x} \cdot \omega_{\mathrm{K}} \cdot r_{\mathrm{K}}
$$

Dividing the left and right parts of the equation (18) into $\omega_{\mathrm{K}}$, we obtain the following expression after rearrangement:

$$
M_{\mathrm{K}}=M_{f} \cdot \frac{r_{\mathrm{K}}}{r_{\text {म }}}+R_{x} \cdot r_{\text {म }}=\mathrm{a} \cdot R_{z} \cdot \frac{r_{\text {Д }}}{r_{\mathrm{K}}}+R_{x} \cdot r_{\text {म }}=\mathrm{f} \cdot R_{z} \cdot \frac{r_{\text {Д }}^{2}}{r_{\mathrm{K}}}+R_{x} \cdot r_{\text {Д }}
$$

The power balance equation (3) can be represented in the form (with the account of the wheel power output-input ratio $\eta_{\mathrm{K}}^{\text {сил }}$ ).

$$
M_{\mathrm{K}} \cdot \eta_{\mathrm{\kappa}}^{\text {сил }}=M_{f}+R_{x} \cdot r_{\text {д }}
$$

From the expression (20), taking account the equation (19), we obtain:

$$
\eta_{\mathrm{K}}^{\text {сил }}=\frac{M_{f}+R_{x} \cdot r_{\text {Д }}}{M_{f} \cdot \frac{r_{\text {Д }}}{r_{\mathrm{K}}}+R_{x} \cdot r_{\text {म }}}=\frac{f+\frac{R_{\chi}}{R_{Z}}}{f \cdot \frac{r_{\text {A }}}{r_{\mathrm{K}}}+\frac{R_{\chi}}{R_{Z}}}
$$

Where: - wheel rolling resistance factor.

$$
f=\frac{a}{r_{\text {д }}}
$$

The cyclic output-input ratio of a wheeled mover for the period of time $\mathrm{T}$ can be defined as follows:

$$
\eta_{\mathrm{\kappa}}^{\text {цикл }}=\frac{1}{\mathrm{~T}} \int_{0}^{\mathrm{T}} \frac{r_{\mathrm{K}}(t)}{r_{\mathrm{\mu}}(t)} d t
$$

Where $r_{\mathrm{K}}(t), r_{\mathrm{д}}(t)$ - time control functions of the kinematic and dynamic radii.

Therefore, the inconsistency specified in the papers [7,11] is explained by the fact that the wheel power balance equation has an instantaneous wheel output-input ratio $\eta_{\mathrm{K}}^{\mathrm{MrH}}$ while the force balance equation has a force output-input ratio $\eta_{\mathrm{K}}^{\text {сил }}$.

Therefore, if we consider the wheel as a deformed body rather than a solid one, it eliminates the inconsistencies between the force and power balance equations of the drive wheel in the equilibrium. The obtained expressions for an instantaneous output-input ratio take into account kinematic $r_{\mathrm{K}}$ and dynamic $r_{\mathrm{д}}$ drive wheel radii. The obtained expressions for a force output-input ratio (see (21)) make us think over the issue what is the rolling resistance moment $M_{f}$ - designation or internal effort? Apparently, it is an external effort for a car, but if we consider a four-phase mechanism of the car undercarriage (as it is suggested 
in the paper [13]), including a road as a separate standing element, an instantaneous rolling resistance of fore and back wheels will represent an internal effort. That is why in the equation (21) the input rolling resistance factor for a force output-input ratio is $f$.

\section{Conclusions}

1. The inconsistencies between the equations for the car drive wheel force and power balance equations are eliminated if we take into account instantaneous and force outputinput ratios.

2. The obtained expressions for instantaneous, force and cyclic drive wheel output-input ratios give us an opportunity to specify the car traction calculation.

\section{References}

1. Pozhidayev S.P., On Theory of Elastic Wheel Quality in Terms of Mechnaics, Motor Car Industry, No.1. P.16-17 (2014).

2. Pozhidayev S.P., On Useful Mechanical Effect and Car Energy Efficiency, Автомеханик України, No.3, P.18-21(2015).

3. Evsyeev P.P., Efficient Car Engine Output-Input Ratio, Motor Car Industry, No.4, P.12 - 14 (2006).

4. Pozhidayev P.K., Issues on Elastic Wheel Radius, R\&D Journal "Motor Car Transport", No.4 (20), P.6 - 8 (2014).

5. T.A. Balabina, N.P. Balovnev, V.A. Ivanov. S.I. Chepurnoy, Influence of Parameters and Contact Conditions of Wheel Elasticity on Their Power and Kinematic Characteristics, News Bulleting of Moscow State Technical University "MAMI", No.1 (15), V.1, P.28 - 32 (2013).

6. Kopotilov V.I., Key Parameters of Elastic Wheel Rolling at Movement Along Hard Surface, Oil and Gas in Western Siberia: Materials of International Scientific and Technical Conference. T.S. Design, Building and Operation of Transport Systems and Oil\&Gas Storage Systems. Auto-road Problems of Oil-Gas Complex. TyumGNGU, P.201-205 (2015).

7. V.I.Kopotilov, L.B. Parkhomenko, Analysis of Force and Power Balance Equations for Car Drive Wheel, Oil and Gas in Western Siberia: Materials of International Scientific and Technical Conference. T.S. Design, Building and Operation of Transport Systems and Oil\&Gas Storage Systems. Auto-road Problems of Oil-Gas Complex. TyumGNGU, Editor P.V. Yevtin. - Tyumen.: TyumGNGU, P. 206-209 (2015).

8. Kopotilov V.I., Theoretical Analysis of Car Drive Wheel Radii, Truck. Monthly and daily R\&D journal, M.: 000 -Mashinostroyeniye, 32, P.34-39 (2013).

9. Yu.G. Gorshkov. I.V. Zainiyev, Mobile Device Power Losses due to Pneumatic Wheeled Mover Rolling, Tractors and Agricultural Machines, No.10, P.16-19 (2009).

10. Tarasik V.P., Theory of Car Motion: Manual for Higher Education Institutions (SaintPetersburg: BKhV - Saint-Petersburg, 2006)

11. V.A. Petrushov, V.V, Moskovkin, A.N. Evgrafov, Car Power Balance (M.:Mashinostroyeniye, 1984). 
12. U.A. Abdulgazis, A.U. Abdulgazis, D.M. Podrigalo, Wheel Dynamics and Road Holding (Simferopol : DIAIPI, 2010).

13. Podrigalo, M.A., Car Wheel Rolling and Definition of Notion "Pulling Power", Motor Car Industry, No.1, P.25 - 26 (2007). 